\title{
Investigating the influence of built-up edge on forces and surface roughness in micro scale orthogonal machining of titanium alloy Ti6Al4V
}

\author{
Samad Nadimi Bavil Oliaei ${ }^{a}$, Yiğit Karpat ${ }^{a, b, *}$ \\ a Bilkent University, Department of Mechanical Engineering, Micro System Design and Manufacturing Center, Bilkent, Ankara, Turkey \\ ${ }^{\mathrm{b}}$ Bilkent University, Department of Industrial Engineering, Bilkent, Ankara, Turkey
}

\section{A R T I C L E I N F O}

\section{Article history:}

Received 3 November 2015

Received in revised form 14 March 2016

Accepted 7 April 2016

Available online 11 April 2016

\section{Keywords:}

Cutting

Micro machining

Built-up edge

Titanium alloy

\begin{abstract}
A B S T R A C T
The edge geometry of cutting tools directly influences the chip formation mechanism in micromechanical machining, where the edge radius and uncut chip thickness are in the same order of magnitude. An uncut chip thickness that is smaller than the cutting edge radius results in a large negative rake angle during machining, and built-up edge formation then affects the mechanics of the process. In this study, micro-scale orthogonal cutting tests on titanium alloy Ti6Al4V were conducted to investigate the influence of built-up edge formation on the machining forces and surface roughness. Cutting edges in these tests are engineered using wire EDM technique to have an edge radius of around $2 \mu \mathrm{m}$ and clearance angles of $7^{\circ}$ and $14^{\circ}$. It is observed that machining process inputs (uncut chip thickness, cutting speed, and clearance angle) affect the size of the built-up edge, which in turn affect the process outputs. It is observed that built-up edge formation protects the cutting edge from flank and crater wear under micro machining conditions and the influence of built-up edge on the surface roughness varies depending on the cutting speed and uncut chip thickness. Our findings also indicate a close relationship between the minimum uncut chip thickness and the mean roughness depth $\left(\mathrm{R}_{\mathrm{z}}\right)$ of the machined surface. The minimum uncut chip thickness is found to be around $10 \%$ of the edge radius in the presence of built-up edge.
\end{abstract}

(C) 2016 Elsevier B.V. All rights reserved.

\section{Introduction}

Mechanical micro machining is defined as the machining of precision parts made out of a wide range of engineering materials with complex surfaces (Dornfeld et al., 2006). A solid understanding of the mechanics of cutting at the micro scale is crucial in building predictive models and controlling the quality of micro parts. A commonly observed phenomenon which appears during continuous chip formation is built-up edge (BUE) and it is known to affect surface roughness and tool wear. A BUE consists of material layers which are deposited onto the tool surface, changing the tool geometry and, hence, the mechanics of the process. A stable and thin BUE is known to protect the cutting edge (Kalpakjian and Schmid, 2010).

\footnotetext{
* Corresponding author at: Bilkent University, Department of Industrial Engineering, Bilkent, Ankara, Turkey.

E-mail address: ykarpat@bilkent.edu.tr (Y. Karpat).
}

Small uncut chip thicknesses machined with tools having a comparable edge radius creates suitable conditions for BUE formation in micro scale machining. Gaining a better understanding of the influence of BUE on process outputs have resulted in an increased interest in machining research.

Due to the micro cutting tool fabrication process and tool material grain size limitations, the edge radius cannot be easily decreased without sacrificing the strength of the tool, which in turn affects the chip formation process and the surface quality of the machined workpiece. Weule et al. (2002) showed the importance of edge roundness when tungsten carbide micro end mills are used to machine ferrous materials. Woon et al. (2008) studied the interaction between uncut chip thickness and edge radius using experimental and finite element based techniques when micro machining AISI 1045. They showed the edge radius acting like a negative rake angle and found that a constant stagnation point on the tool exists for a large range of uncut chip thickness values. However, in an earlier study, Waldorf et al. (1999), studied ploughing 

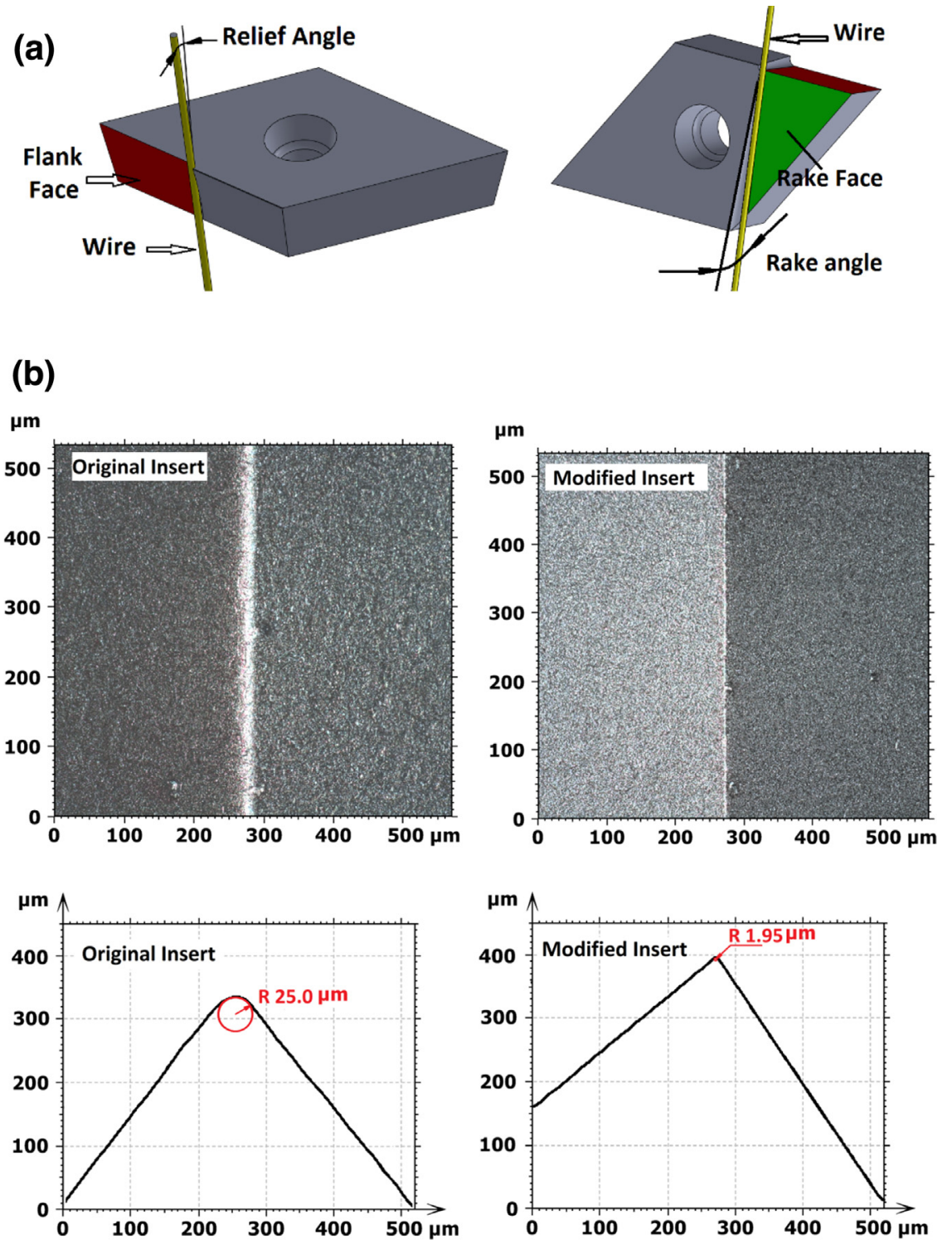

Fig. 1. (a) Schematic of wire-EDM processing to obtain required rake and clearance angles, (b) Edge radius measurement of the insert after edge preparation.

Table 1

Experimental conditions.

\begin{tabular}{|c|c|c|c|}
\hline $\begin{array}{l}\text { Initial Cutting } \\
\text { Edge Radius }\end{array}$ & $\begin{array}{l}\text { Clearance } \\
\text { Angle }\end{array}$ & $\begin{array}{l}\text { Uncut Chip } \\
\text { Thickness }\end{array}$ & $\begin{array}{l}\text { Cutting Speed } \\
(\mathrm{m} / \mathrm{min})\end{array}$ \\
\hline $1.95 \mu \mathrm{m}$ & $7-14$ & $0.2-0.4-0.6-0.8-1 \mu \mathrm{m}$ & $30-47-62-78$ \\
\hline
\end{tabular}

models during orthogonal cutting and found that a stable built-up model described experimental observations better than a stagnation point model. Fang and Dewhurst (2005) used slip line field analysis to predict the size of the built-up edge during machining. Karpat and Özel (2008) also presented a slip line field based approach for machining with round edged tools, including built-up edge. Karpat (2009) considered the influence of cutting edge radius including built-up edge during micro scale machining and studied the effect of fracture on machining outputs. Childs (2013) developed a finite element model to predict built-up edge formation during machining of steel by integrating a damage model. Some preliminary results on simulating built-up edge during micro scale machining were also presented in Childs (2013). A detailed investigation of how built-up edge influences micro scale machining is the aim of this study.
Table 2

EDX analysis of surface on the tool.

\begin{tabular}{lll}
\hline $\begin{array}{l}\text { Insert Surface } \\
\text { before machining }\end{array}$ & Analysis of BUE & $\begin{array}{l}\text { Insert Surface } \\
\text { after Cleaning }\end{array}$ \\
\hline Co $\% 5.19$ & $\mathrm{Al} \% 5.66$ & $\mathrm{Co} \% 4.65$ \\
$\mathrm{~W} \% 94.81$ & $\mathrm{Ti} \% 82.82$ & $\mathrm{~W} \% 93.95$ \\
& $\mathrm{~V} \% 3.46$ & \\
& $\mathrm{Co} \% 0.59$ & \\
& $\mathrm{~W} \% 7.48$ & \\
\hline
\end{tabular}

In micro scale machining, the cutting tool edge radius and the amount of material being cut are in the same order of magnitude. There is a value of uncut chip thickness after which continuous chip formation ceases. This critical value is defined as minimum chip thickness, which is known to be a function of the tool material, cutting edge radius, and workpiece material (Ikawa et al., 1992). Lucca et al. $(1991,1993)$ indicated the importance of the sliding and ploughing at the tool workpiece interface due to edge radius of the tool during ultra precision machining conditions. Kim et al. (2004) analyzed the periodicity of forces during micro milling and identified the transition between non-cutting and cutting regimes near 

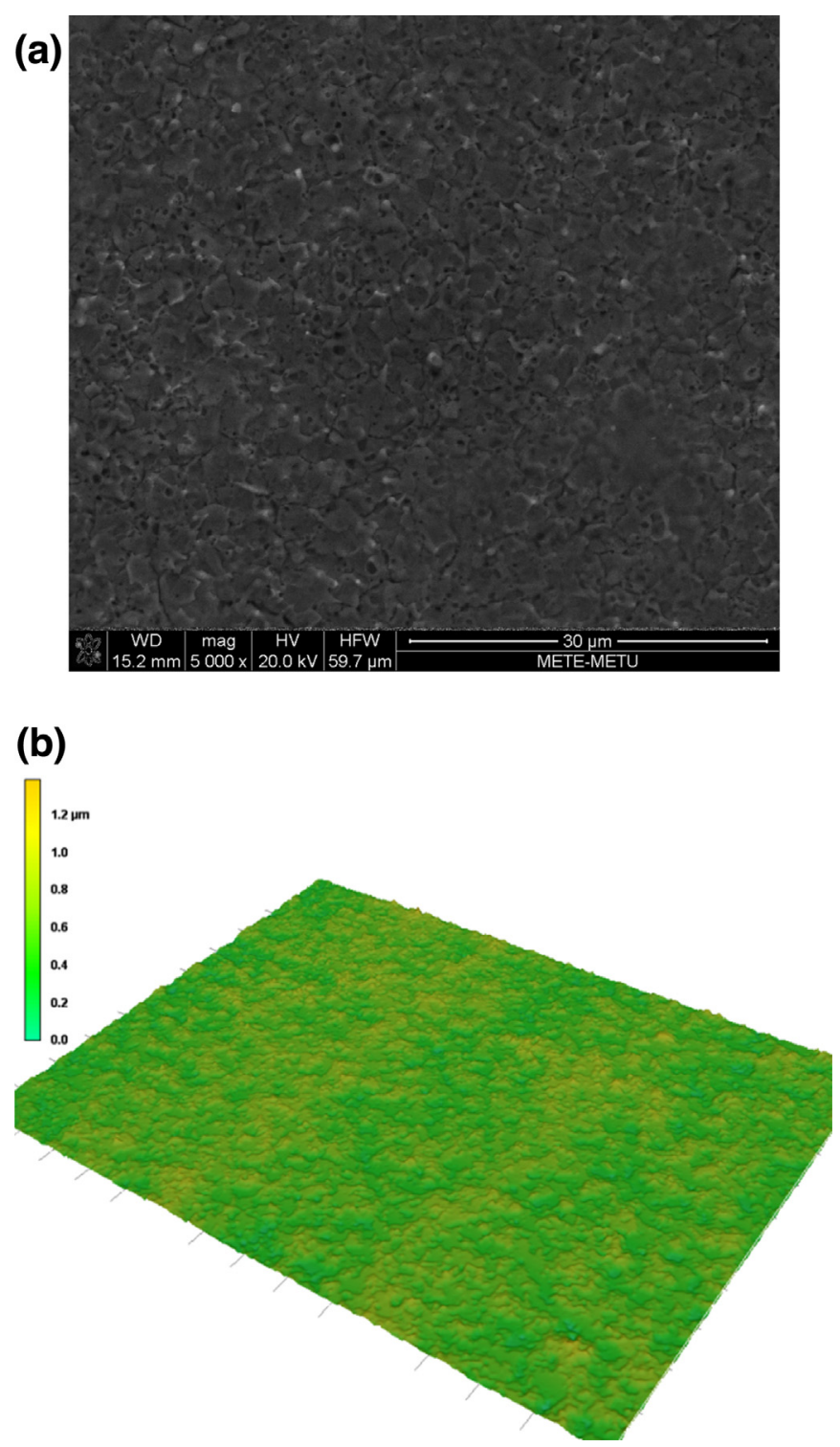

Fig. 2. Investigation of the tool surface after wire EDM (a) SEM image, (b) Surface topography of the rake face.

the minimum chip thickness value. They concluded that the periodicity of cutting forces is affected by the minimum chip thickness, feed per tooth, and cutting position angle. They observed a local maximum in the thrust forces that takes place around minimum chip thickness value. Jun et al. (2006) investigated the dynamics of micro end milling and observed peaks in the thrust force around minimum chip thickness during micro machining of ferrite and pearlite. They concluded that the minimum chip thickness effect causes instability at low feed rates. The same phenomenon was observed by Liu et al. (2004) and named as feed rate instability. Son et al. (2005) studied minimum uncut chip thickness and its relation to the edge radius during diamond turning of various materials. They developed a relationship between minimum uncut chip thickness, friction angle, and edge radius. Malekian et al. (2012) used a minimum energy based method to model minimum uncut chip thickness while machining aluminum alloy. They found the stagnation point to be approximately $23 \%$ of the edge radius, and it is not a constant point but a region on the tool. Cuba Ramos et al. (2012) emphasized the importance of built-up edge formation during transition from ploughing to cutting during micro scale machining of AISI 1045 and developed a new model for the estimation of mini- mum chip thickness. In this study, minimum uncut chip thickness phenomenon in the presence of BUE is investigated by focusing on the interaction between BUE and surface roughness.

Due to its high reactivity with cutting tool materials and its low thermal conductivity, titanium alloys are considered difficultto-cut, so rapid tool wear is an important issue that affects the quality of the machined products. BUE formation during machining of titanium under macro scale machining conditions has been well studied in literature. The issues related to BUE and tool wear have been summarized in Ezugwu and Wang (1997), Armendia et al. (2010) and Pramanik and Littlefair (2015). Thepsonthi and Özel (2015) studied micro milling of titanium alloy Ti6AL4V and observed BUE when cutting edge is worn. The wear mechanisms of titanium alloys were shown to be quite different from steels and nickel alloys in Hartung and Kramer (1982). It was shown that tool wear was greatly reduced when adhesion occurs between tool and chip. The adhesion layer prevents sliding at the interface and improves tool life under certain conditions. In a recent study, Kümmel et al. (2014) showed that tool wear performance may be improved when cutting tools with intentional built-up edge are employed in machining. Kümmel et al. (2015) used laser surface 

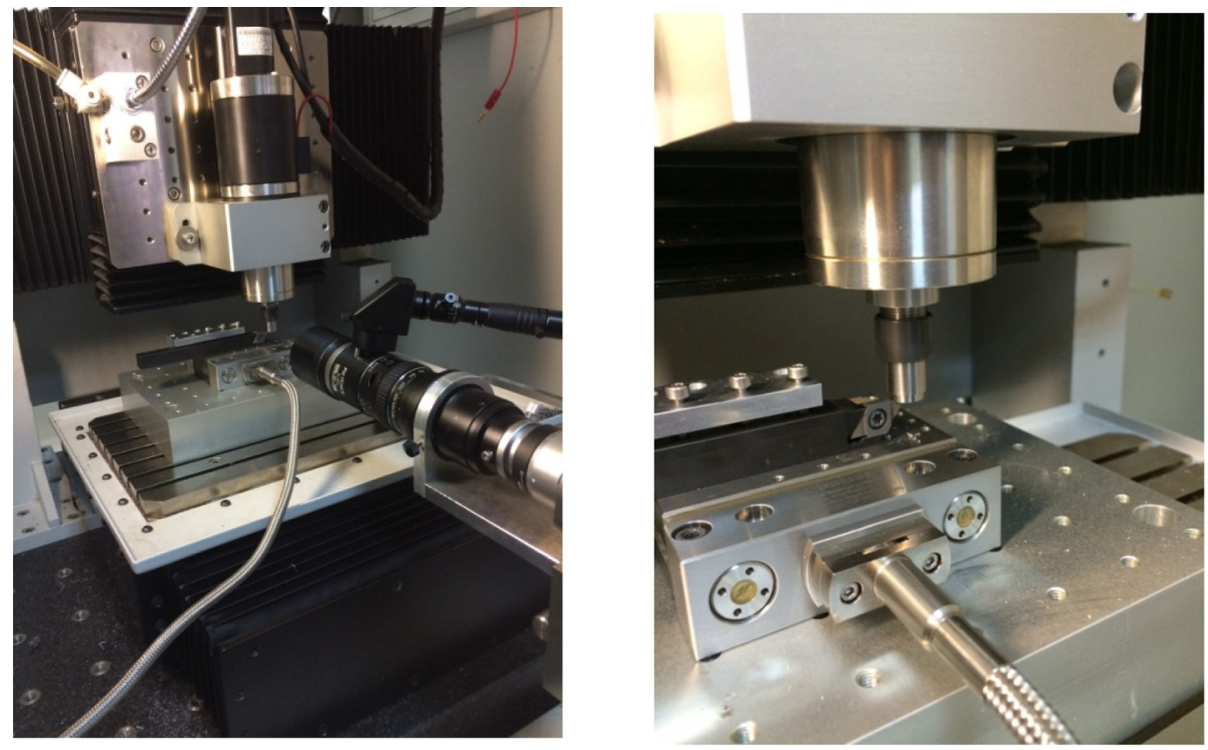

(a)

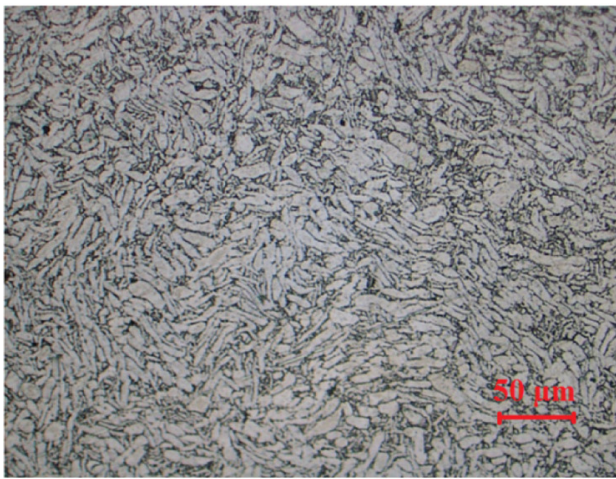

(b)

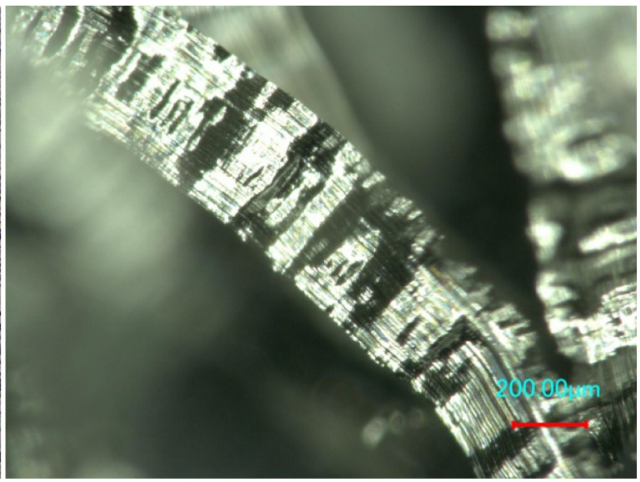

(c)

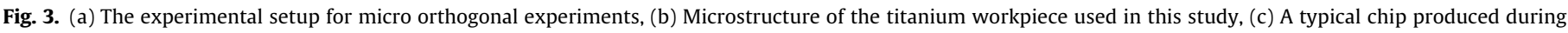
micro machining experiments.

texturing to create different dimple structures and channels on the rake face of the tool. The dimple textures are shown to increase BUE adhesion on the tool. In this study, electrical discharge machining (EDM) technique is used to prepare the cutting edges. Using EDM process creates micro scale craters on the surface of the tool, which may also promote BUE adhesion during machining.

In this study, the influence of built-up edge on process forces, surface quality and minimum chip thickness during micro machining of titanium alloy has been investigated in detail. Cutting edges with small edge radii were specifically fabricated and uncut chip thickness values were set to be less than the edge radius to create micro scale machining conditions. Cutting edges and machined surfaces were investigated after the tests to reveal the influence of built-up edge on process outputs.

\section{Experimental procedure}

\subsection{Fabrication of cutting edge micro geometry}

The cutting edge micro geometry is obtained through micro wire electric discharge machining (wire EDM) technique. The EDM technique is advantageous in terms of controlling the micro geometry of the edge. The feasibility of edge preparation using EDM tech- nique was shown by Yussefian et al. (2010). In this study, the edge geometries of the uncoated carbide tools (DCMW 11 T3 04H13A) with $0^{\circ}$ rake angle are modified by using the wire EDM device (Sodick AP250L). The $U$ and $V$ axes of the wire EDM machine are utilized to obtain necessary clearance (relief) angles on the cutting edges as shown in Fig. 1a. An EDM wire diameter of $100 \mu \mathrm{m}$ was used. The wire EDM machine uses oil as dielectric fluid in order to obtain superior surface quality. Cutting edges with two different clearance angles $\left(7^{\circ}\right.$ and $\left.14^{\circ}\right)$ were prepared and edge radii of each insert were measured. Fig. $1 \mathrm{~b}$ shows the profile of a cutting edge before and after edge preparation with EDM machining.

A laser scanning microscope (Keyence VK-X100) was used to measure the edge radius and clearance angle of the tools. The edge radius after EDM machining is measured as $1.95 \mu \mathrm{m}$ where the initial edge radius of the insert was $25 \mu \mathrm{m}$. A detailed discussion on the influence of edge radius on machining and the uncertainties related to its measurements were described in Denkena and Biermann (2014). Scanning electron microscope image of the tool surface after wire EDM is shown in Fig. 2a. The surface roughness $\left(R_{a}\right)$ of the insert was measured as $0.11 \mu \mathrm{m}$ using a laser scanning microscope after the EDM process which is shown in Fig. $2 \mathrm{~b}$. 
(a)

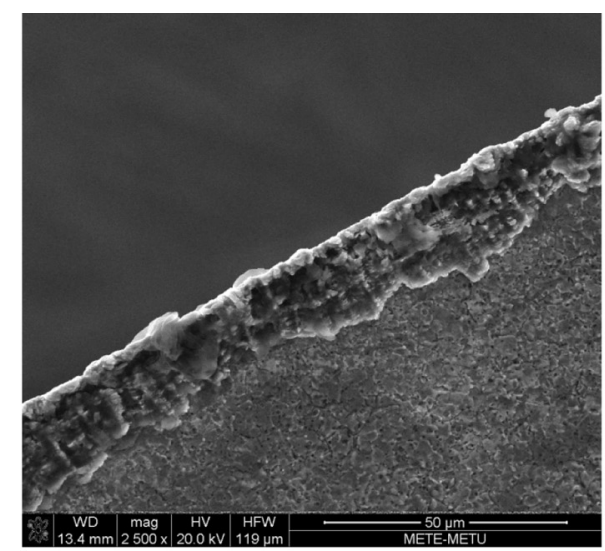

(b)

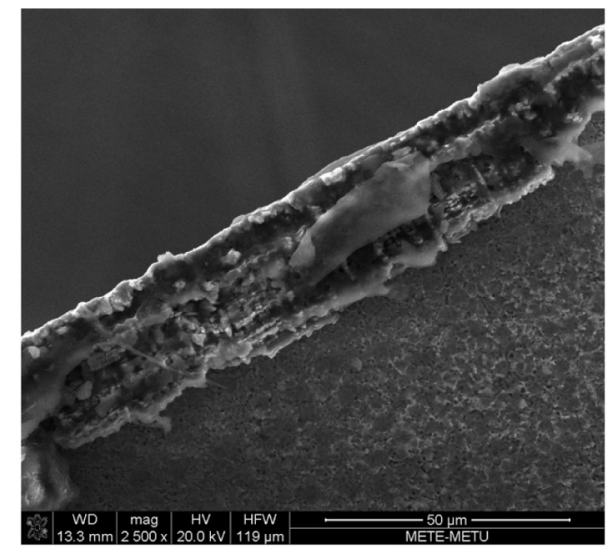

(c)

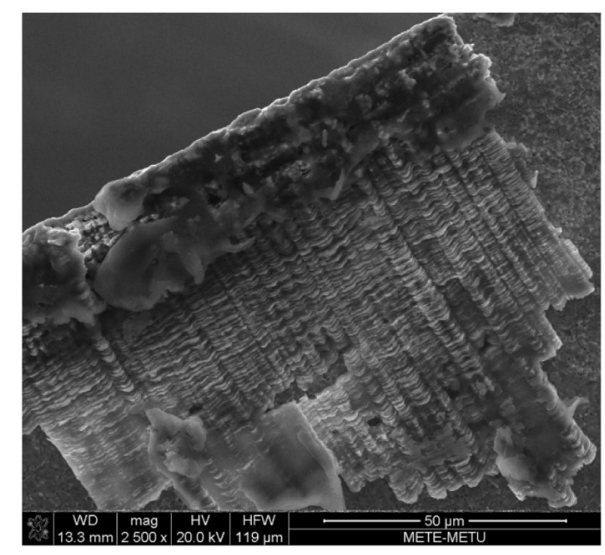

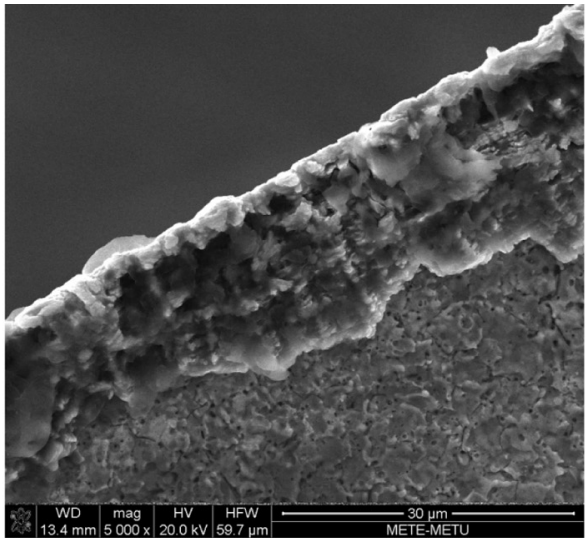
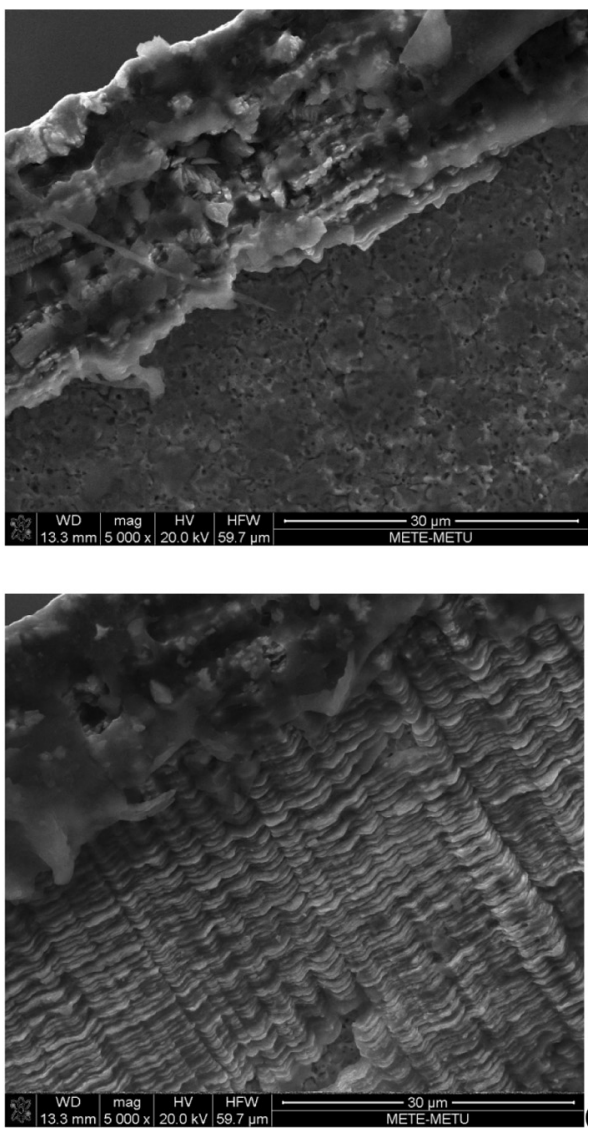

Fig. 4. SEM images of the cutting edges after machining tests: a) $0.2 \mu \mathrm{m}, \mathrm{b}) 0.4 \mu \mathrm{m}, \mathrm{c}) 0.6 \mu \mathrm{m}$.

\subsection{Experimental setup for orthogonal micro cutting tests}

A three-axis hybrid micro machining center (Mikrotools DT110), capable of performing micro turning processes, was used to conduct micro orthogonal cutting experiments. The machine is equipped with a spindle with maximum rotational speed of $3000 \mathrm{rpm}$. Titanium alloy shafts with $10 \mathrm{~mm}$ outer diameter and $0.25-0.35 \mathrm{~mm}$ wall thickness were prepared. Only one end of the shaft was machined to be hollow. The depth of hollow side was kept at 3-4 mm. Inserts with engineered edges were placed on a SDACR $1212 \mathrm{~K} 11 \mathrm{~S}$ tool holder, which was then attached to the Kistler mini dynamometer (9256, max $250 \mathrm{~N}$ ) as shown in Fig. 3. Micro machining forces were measured and transferred to a PC through a data acquisition card (National Instruments PXI series). The titanium alloy Ti6Al4 V $(\alpha+\beta)$ work material with lamellar microstructure (grains of average $25 \mu \mathrm{m}$ length and $5 \mu \mathrm{m}$ thickness), which is shown to be suitable for micromachining applications in Attanasio et al. (2013), was used in experiments (Fig. 3b). It had a hardness of $328 \mathrm{HV}$. The workpiece was fed towards the cutting tool with necessary feed rate to obtain the required uncut chip thickness during orthogonal tests. The machining time and distance were checked using a high speed microscope to make sure that the desired feed rate was achieved during tests. Fig. $3 \mathrm{c}$ shows a typical continuous chip produced during micro machining experiments.

In this study, micro scale orthogonal machining experiments on titanium alloy Ti6Al4V were performed by using cutting edges specifically produced for that purpose. A different cutting edge was used in each test. Cutting tools have clearance angles of 7 and $14{ }^{\circ}$. The reason for using a low clearance angle is to change machining conditions in the cutting zone and observe its influence on the pro- 


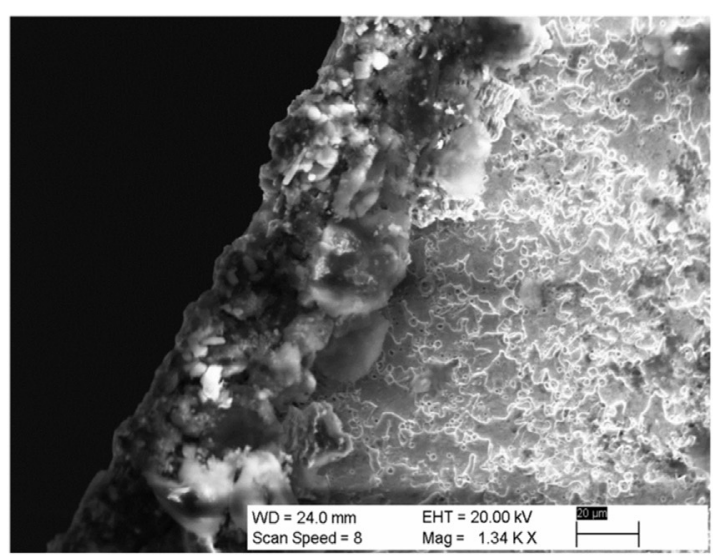

(a)

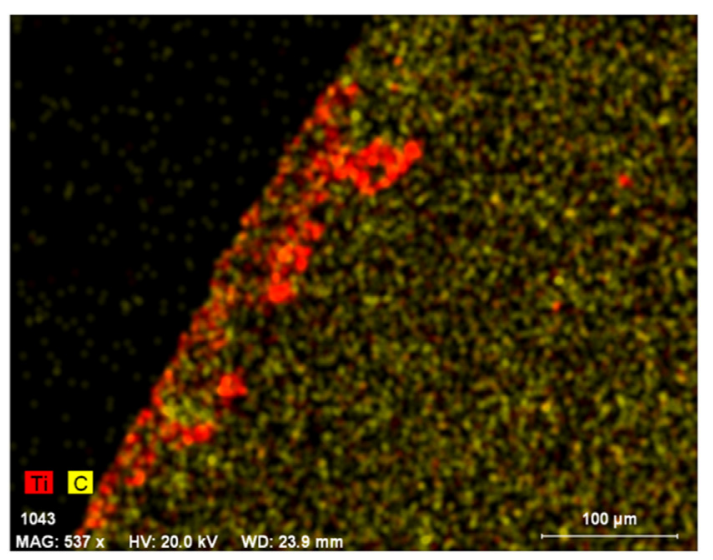

(d)
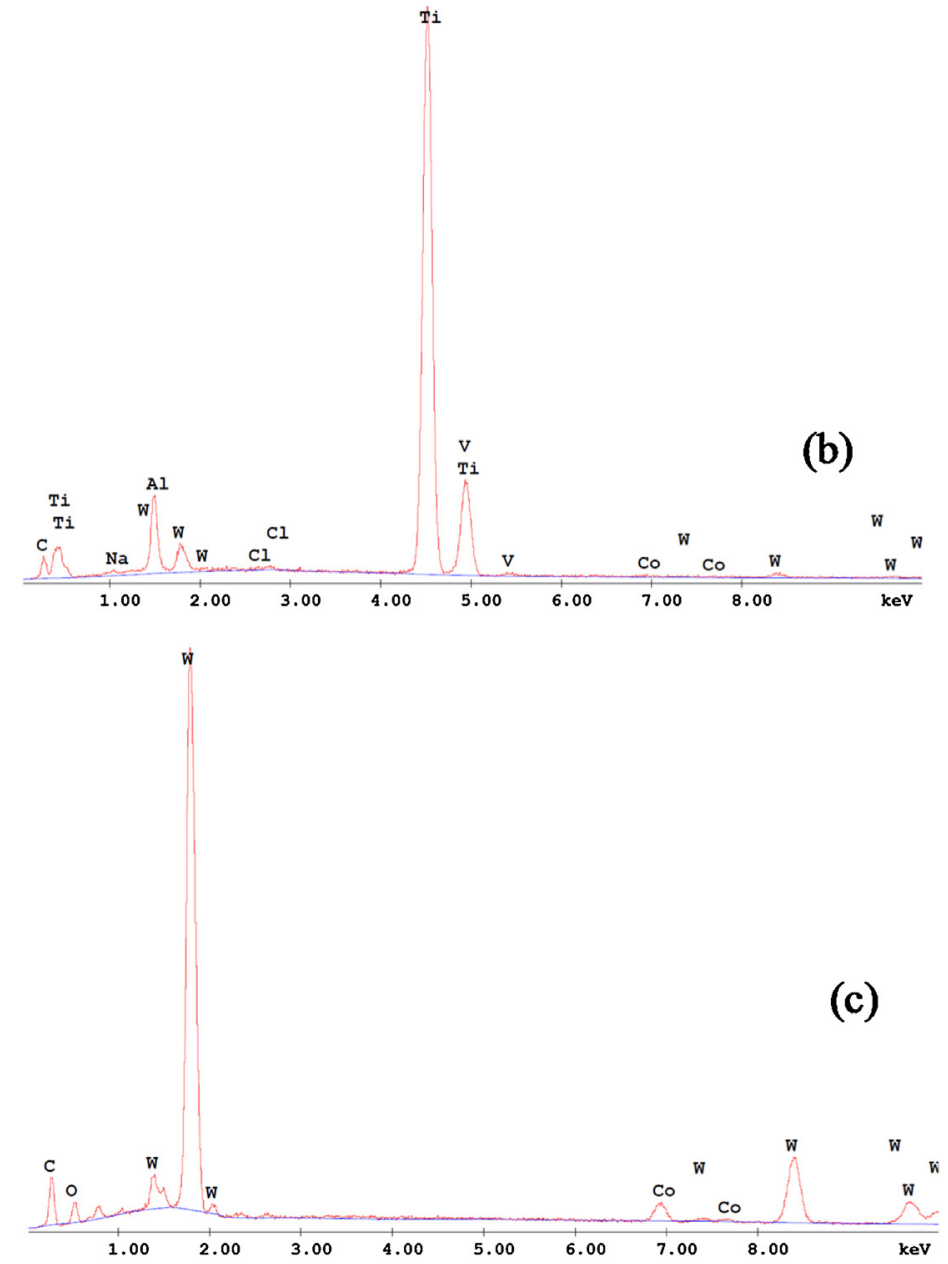

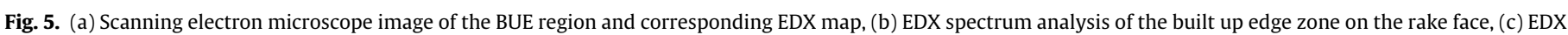
spectrum analysis of the tool surface, (d) Color map of the Ti and C elements on the BUE.

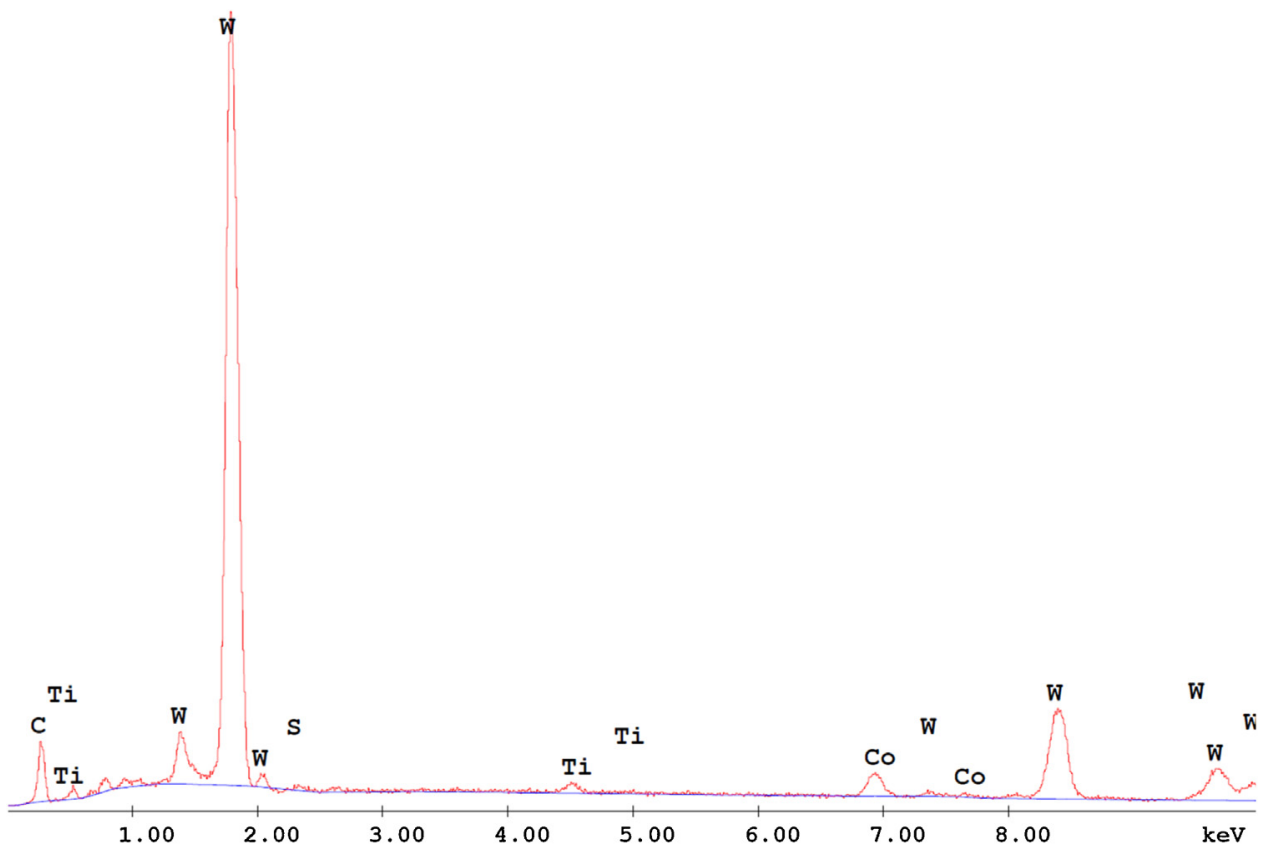

Fig. 6. EDX analysis of the surface underneath BUE. 

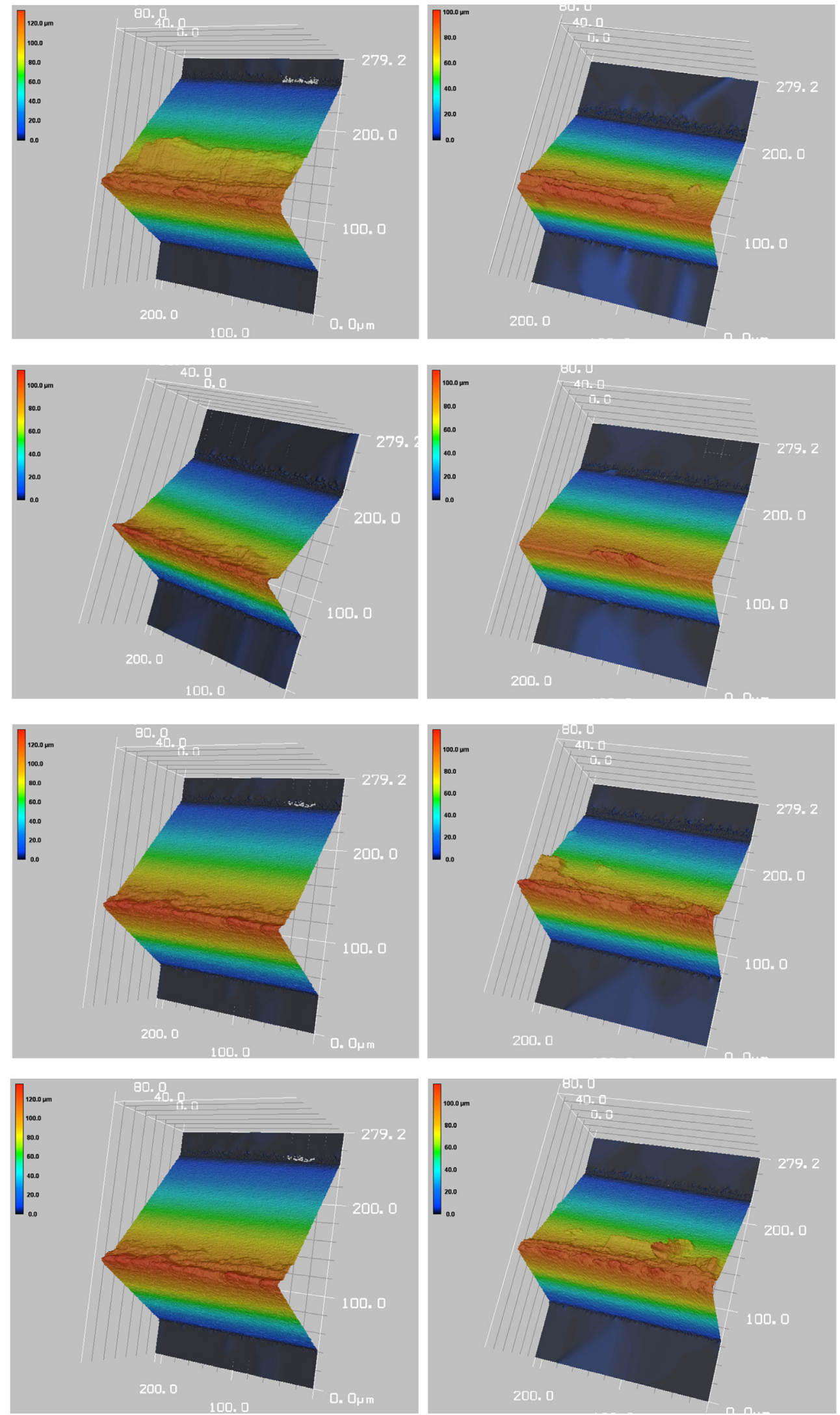

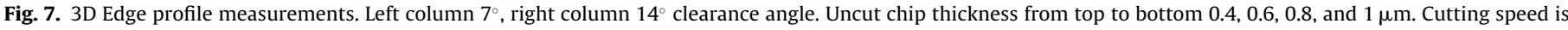
$62 \mathrm{~m} / \mathrm{min}$. 

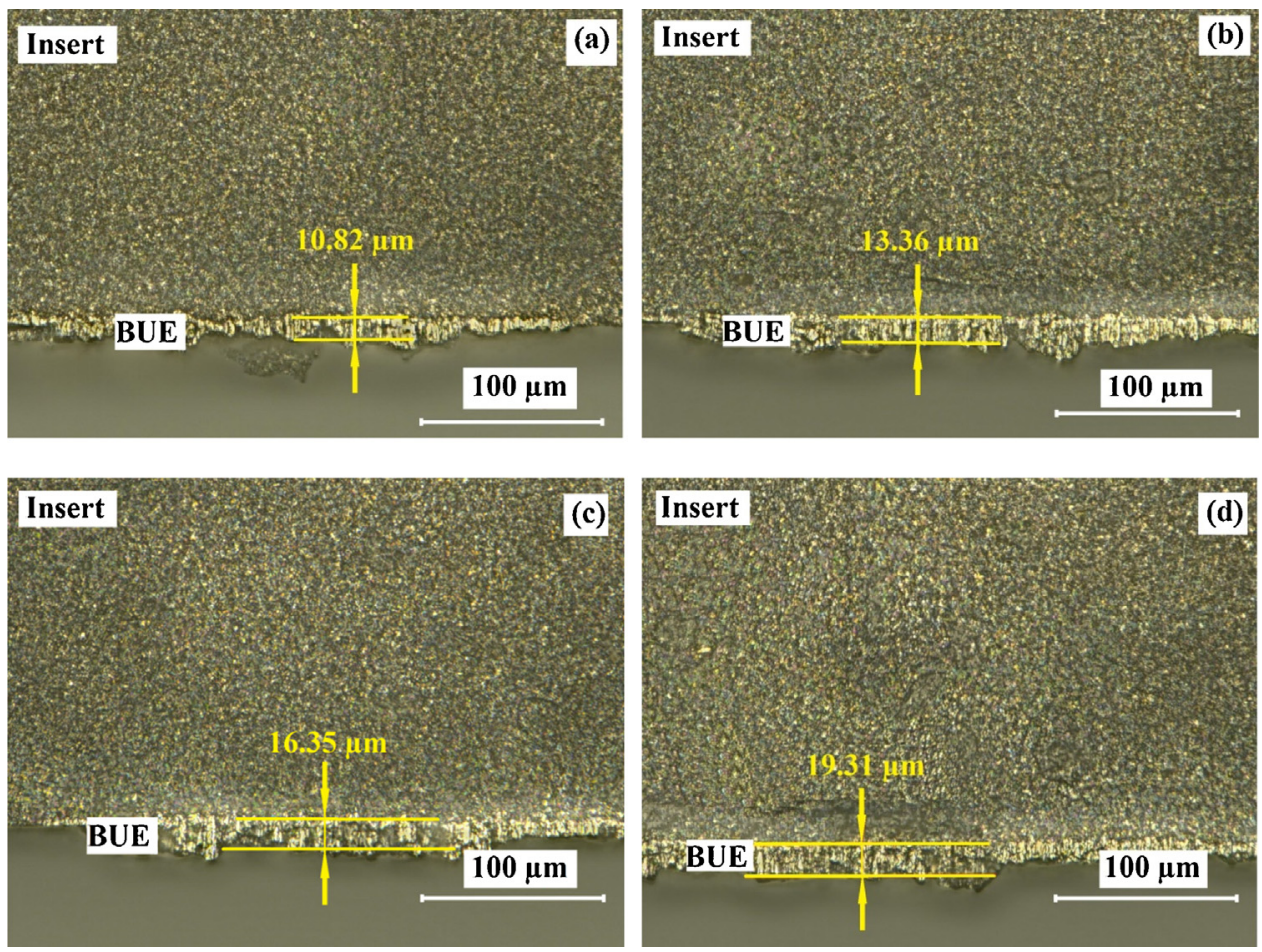

Fig. 8. Increasing BUE tip length with increasing uncut chip thickness a) 0.4, b) 0.6, c) 0.8 , and, d) $1 \mu \mathrm{m}$.
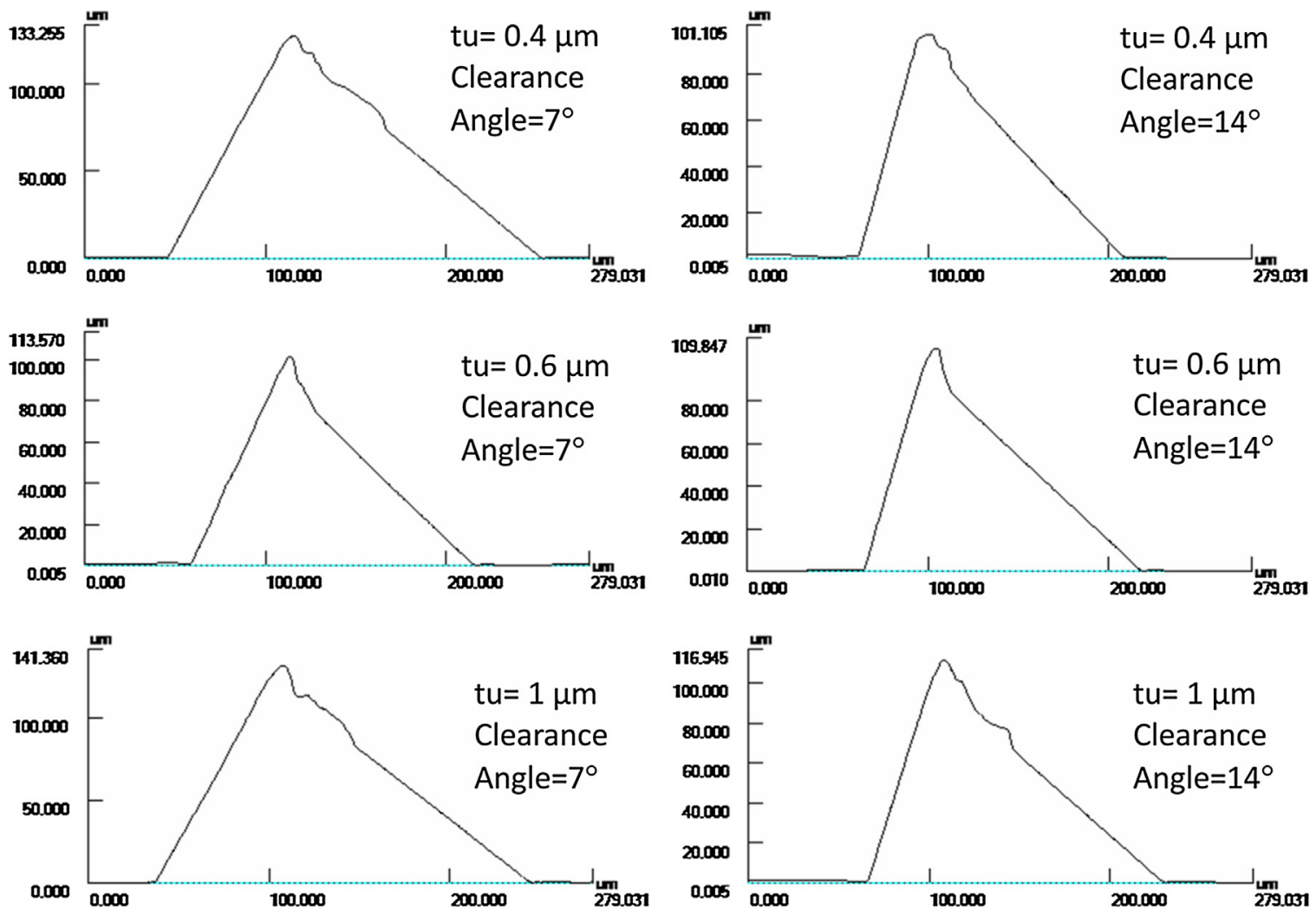

Fig. 9. 2D Edge profile measurements at cutting speed of $62 \mathrm{~m} / \mathrm{min}$. 

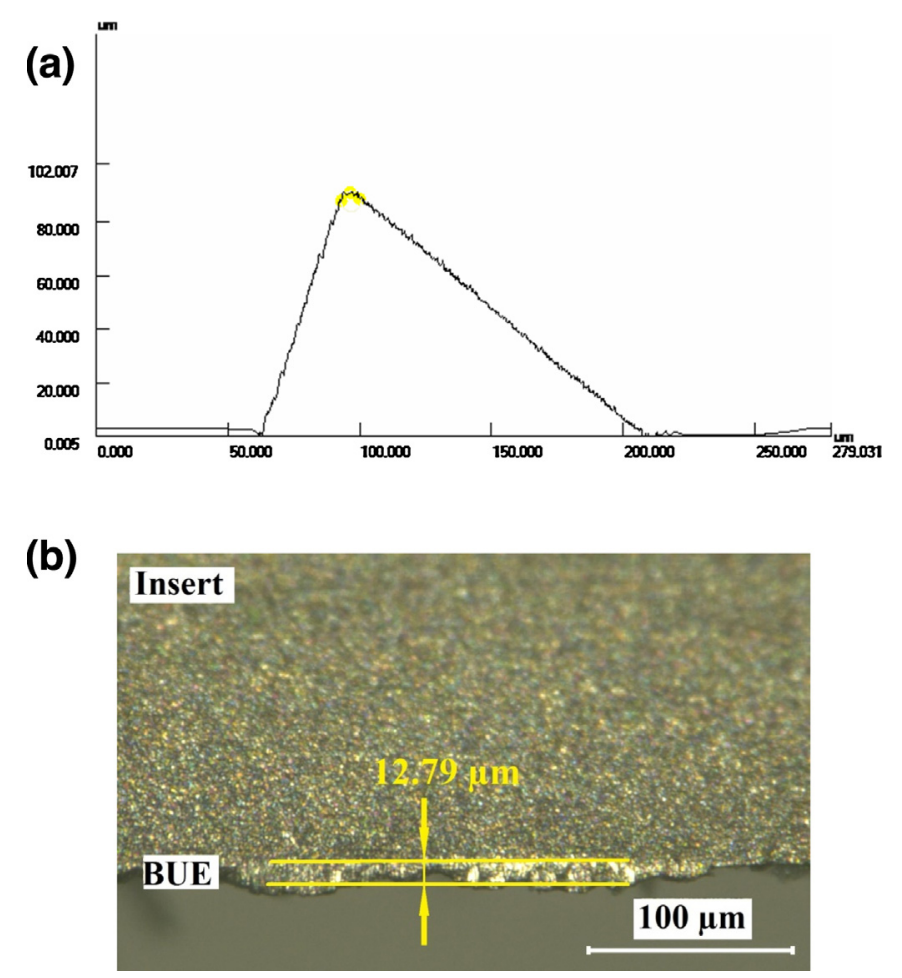

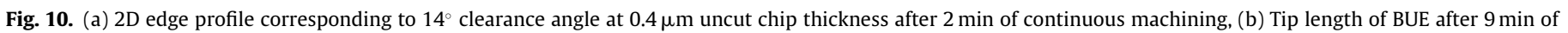
continuous machining ( $62 \mathrm{~m} / \mathrm{min}$ cutting speed).

cess outputs such as built up edge formation and surface roughness. A range of cutting speed values was considered, set at $30,47,62$, and $78 \mathrm{~m} / \mathrm{min}$ based on practical machining conditions of titanium alloy Ti6Al4V within the limits of the spindle. Uncut chip thickness values were considered as $0.2,0.4,0.6,0.8$ and $1 \mu \mathrm{m}$, which are all smaller than the edge radius. Experimental conditions are summarized in Table 1 . The forces during micro machining were also measured. The experiments were conducted over $12 \mathrm{~s}$ for each cutting condition during force measurement studies.

\section{Investigation of BUE after micro machining experiments}

Experiments were performed at each condition and the cutting edges of the inserts are investigated after each experiment. Fig. 4 shows the scanning electron microscope image of the rake face of the cutting edge where the built-up edge formation can be clearly seen.

A relatively large BUE length (around 20-100 $\mu \mathrm{m}$ ), compared to the uncut chip thickness is observed. Based on these images, the thickness of the BUE is larger at the tip of the tool and gradually decreases on the tool rake face. Hartung and Kramer (1992) observed built up layer (BUL) and built up edge (BUE) formation while macro scale machining titanium alloy Ti6Al4V with different cutting tool materials. They observed that tool wear is considerably reduced at certain conditions as a layer prevents relative sliding at the tool chip interface and limits the diffusion rate of the tool constituents. At high speeds, this protective layer is removed and tool wear increases quickly. The thickness of this layer is determined by the balance between the rate of diffusion of the tool material through it, and the rate of dissolution of the reaction layer in the work material. They observed the absence of cobalt and a layer of $\mathrm{TiC}$ was formed on the tool surface which was replenished by the carbon atoms removed from the WC grains below. Similar observations were also made by Ikuta et al. (2002), Armendia et al. (2010), Gerez et al. (2009) and Arrazola et al. (2009) under conventional machining cases where elevated temperatures $\left(700-800^{\circ} \mathrm{C}\right)$ exist at the tool chip interface. At micro scale machining the temperature rise at the tool-chip interface is expected to be lower compared to macro scale machining conditions.

In order to investigate the chemical composition of the tool and BUE, an EDX analysis was performed and the results are shown in Fig. 5. A scanning electron microscope image of the BUE region can be seen in Fig. 5a. Titanium, aluminum, and vanadium elements in the built-up edge region can be clearly identified as shown in Fig. $5 \mathrm{~b}$ and its detailed chemical composition is given Table 2 . The EDX analysis of the tool surface before machining is also shown in Fig. $5 \mathrm{c}$ and its chemical composition is also given in Table 2. A color map of Ti and C elements on the BUE and tool surfaces are shown in Fig. 5d. The EDX analysis was performed for all uncut chip thickness values and similar results are observed.

In order to investigate the influence of BUE on the tool-chip interface, the section of the tool under the BUE is also investigated after cleaning it using an ultrasonic process. EDX analysis was repeated on the region where BUE existed. Fig. 6 shows the EDX spectrum of the tool surface where Co (\% 4.65) and W (\% 93.95) was detected. The amount of Co is slightly lower compared to the original tool surface (see Table 2). This is in accordance with the observations of Hartung and Kramer (1982), although the difference is quite low.

Fig. 7 shows the edge profiles obtained through a laser scanning microscope where shapes of built-up edge for each cutting case can be seen. Fig. 8 shows the optical microscope images taken from the flank face of the cutting edges.

Fig. 9 shows edge profiles of cutting edges where the shape of the built up edge around the tool tip can be seen. Based on these images, as uncut chip thickness increases, the average tip length of BUE increases (from around $10 \mu \mathrm{m}$ to $19 \mu \mathrm{m}$ in Fig. 8). The length of BUE on the rake face is longer at lower uncut chip thickness. No significant difference in terms of BUE size was observed due to different clearance angles. 

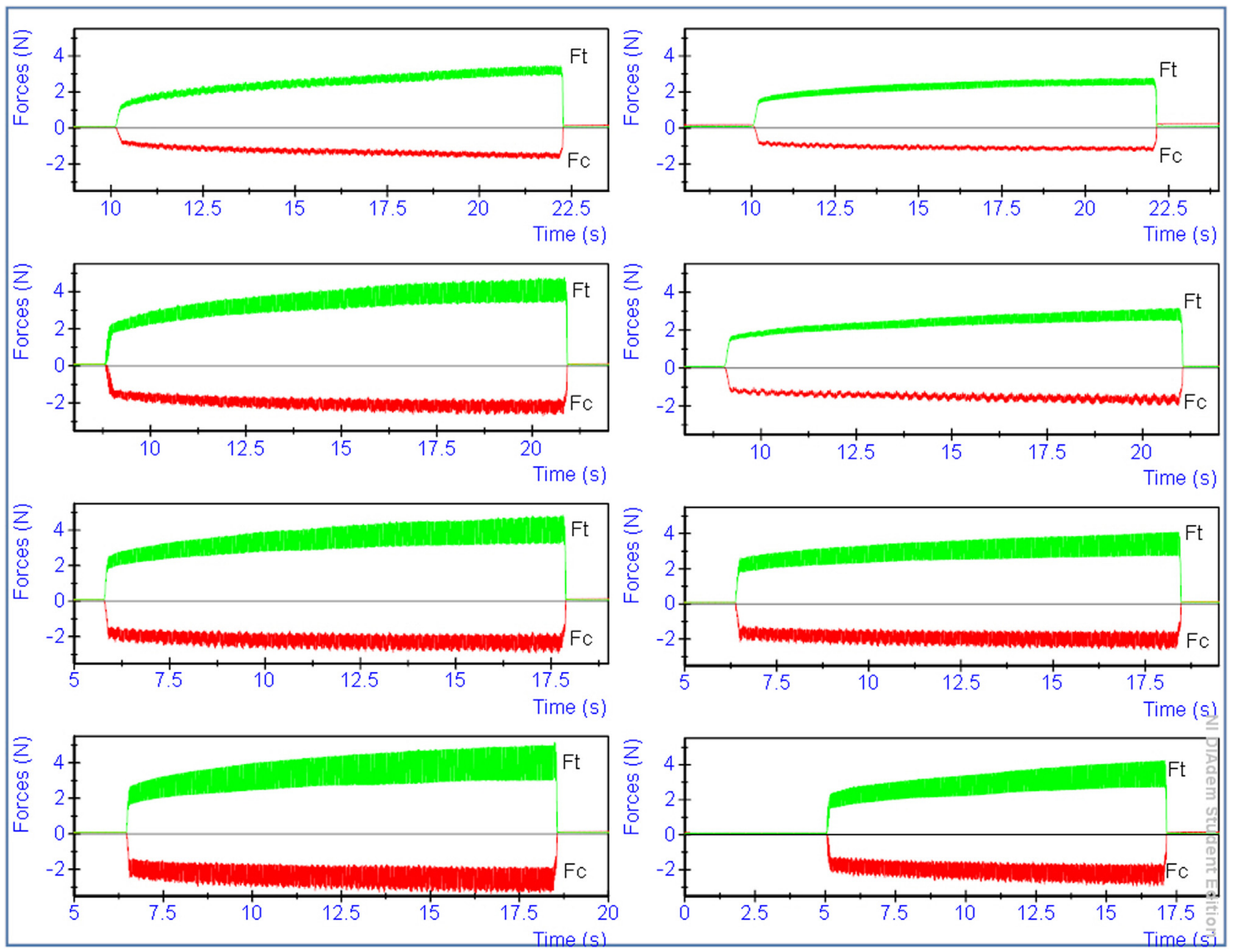

Fig. 11. Force vs, time measurements. Left column $7^{\circ}$, right column $14^{\circ}$ clearance angle. Uncut chip thickness from top to bottom $0.4,0.6,0.8$, and $1 \mu \mathrm{m}$.

Fig. 10a shows the edge profile of the tool after $12 \mathrm{~s}$ of continuous machining after cleaning of the BUE. No sign of crater and flank wear was observed, confirming the protective effect of BUE. However, the edge profile measurement revealed that edge radius increased to $3-4 \mu \mathrm{m}$ at the end of the machining test. Edge rounding is a known form of tool wear during micro scale machining. The machining process was further lengthened to 2 and 9 min of continuous machining. The edge radius was also measured to be around 3-4 $\mu \mathrm{m}$ and again no sign of flank/crater wear was observed on the tool. Fig. 10b shows the tip length of BUE after 9 min of machining from flank side of the tool.

The increase in edge radius may have happened during burnin period of the tool, and it further promotes the accumulation of material in front of the tool. The influence of BUE on machining forces and surface quality are investigated in the next section.

\section{Force measurements during micro scale machining of titanium alloy Ti6AL4V}

Measuring forces during micro machining tests allows the investigation of the process forces in the presence of BUE formation. Fig. 11 shows the force measurements obtained for $7^{\circ}$ and $14^{\circ}$ clearance angle tools for different uncut chip thickness values at $62 \mathrm{~m} / \mathrm{min}$ corresponding to $12 \mathrm{~s}$ of cutting. These measurements correspond to the cutting edge images shown in Fig. 7. Each orthog- onal cutting experiment was repeated at least three times with upsharp tools, and consistent results were obtained. The measured forces were filtered with a low pass filter and average machining forces and force variations around average forces were calculated.

Machining forces were observed to increase at the initial stages of machining, indicating changing contact conditions at the tool tip and BUE formation on the rake face. Increasing average force may be related to edge rounding and increasing force variations may be related to BUE formation. The thrust force $\left(F_{t}\right)$ seems to be affected by the BUE more than the cutting force $\left(\mathrm{F}_{\mathrm{c}}\right)$. Force measurements follow a steady trend indicating the formation of a stable BUE.

Fig. 12 shows the influence of cutting speed on thrust and cutting forces for different uncut chip thickness values. Thrust forces increase with increasing cutting speed for 0.4-0.6 $\mu \mathrm{m}$ uncut chip thickness. There is a significant jump in thrust forces at $62 \mathrm{~m} / \mathrm{min}$ for uncut chip thicknesses of $0.8-1 \mu \mathrm{m}$. These results indicate the influence of increasing built-up edge tip length with increasing uncut chip thickness and cutting speed. As cutting speed is increased to $78 \mathrm{~m} / \mathrm{min}$, thrust forces plateau, which may be due to sharp tip of BUE. Cutting forces mostly peaked around $62 \mathrm{~m} / \mathrm{min}$ and tend to decrease at $78 \mathrm{~m} / \mathrm{min}$.

Fig. 13 shows the average cutting and thrust forces as a function of uncut chip thickness for cutting edges with $7^{\circ}$ and $14^{\circ}$ clearance angles. Although no clear difference in BUE shapes was observed between 7 and 14 clearance angles, force measurements increase as 

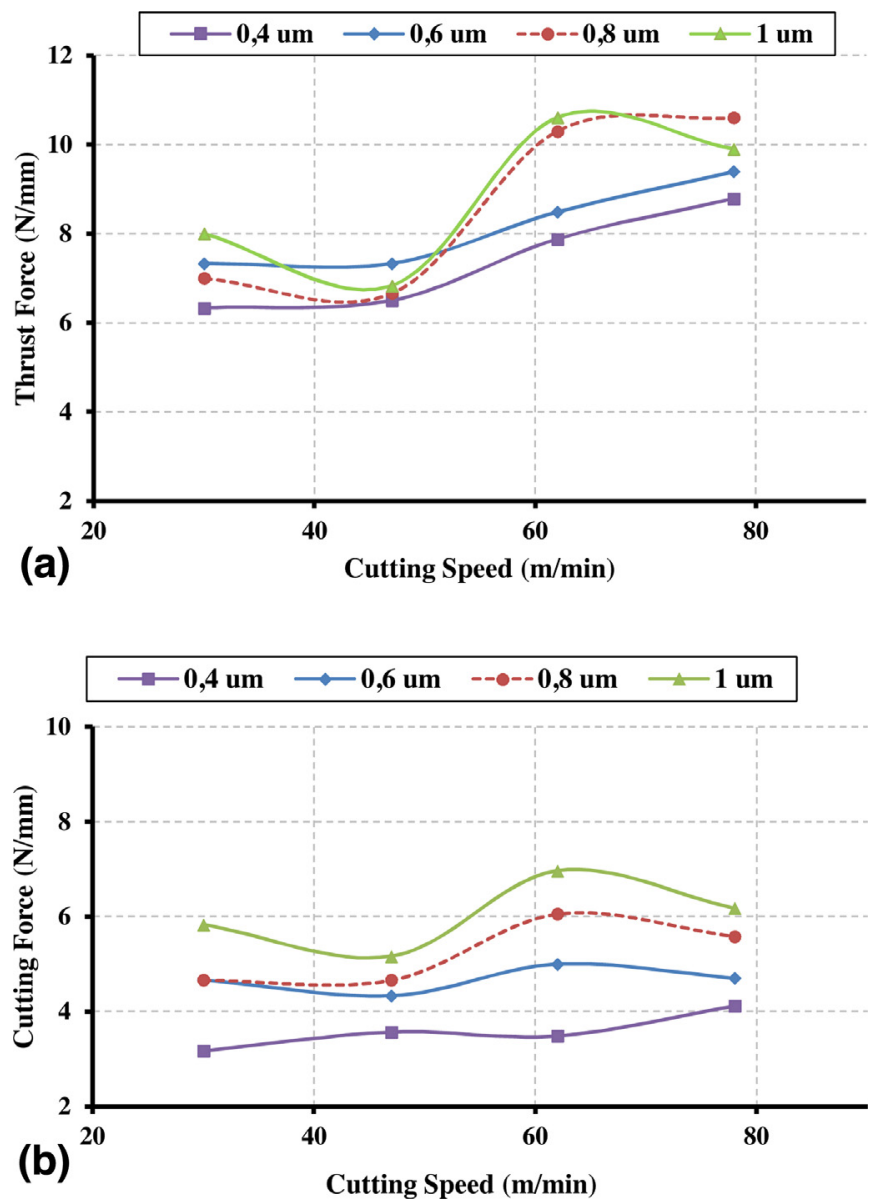

Fig. 12. Mean values of (a) thrust and (b) cutting forces as a function of cutting speed.

clearance angle decreases as expected. Cutting force measurements increase with increasing uncut chip thickness. Thrust force measurements for $7^{\circ}$ clearance angle exhibit a peak at $0.6 \mu \mathrm{m}$ and then plateau between 0.8 and $1 \mu \mathrm{m}$. Thrust force measurement for $14^{\circ}$ clearance angle tool exhibited a similar trend, however it plateaus between 0.8 and $1 \mu \mathrm{m}$ uncut chip thickness. The presence of a builtup edge is known to be important since a large contact area with the workpiece and the tool exists as a result of BUE. Therefore, larger thrust forces are obtained in the measurements.

\section{Effect of BUE on surface roughness}

In micro scale machining, the influence of machining conditions on the surface roughness is quite important as shown in Cuba Ramos et al. (2012). This section investigates the influence of BUE on surface quality. As mentioned earlier, the uncut chip thickness where the thrust force reaches its peak value is identified as minimum chip thickness which defines the transition from a shearing-dominated to a ploughing-dominated machining region. In previous studies, the influence of the surface roughness being cut is usually neglected. In this study, after each test, the machined surfaces are investigated by using a laser scanning microscope (Keyence VK-X100) for contactless surface roughness measurements where arithmetic mean height $(\mathrm{Ra})$ and average distance between the highest peak and lowest valley $(\mathrm{Rz})$ values are considered to study the effect of built-up edge on surface roughness. In measurements, image stitching capability of the laser microscope is used to investigate a large area for detailed surface characterization. Noise filtering and planar tilt correction is applied to a region of interest of $(750 \mu \mathrm{m} \times 200 \mu \mathrm{m})$ before extracting Ra and $\mathrm{Rz}$ val- ues. A cut-off $(\lambda c)$ value of $80 \mu \mathrm{m}$ was used to remove the influence of waviness from surface roughness measurements. Fig. 14 shows surface topologies after machining at $62 \mathrm{~m} / \mathrm{min}$ at 0.4 and $1 \mu \mathrm{m}$ uncut chip thicknesses. The ridges on the machined surface due to non uniform BUE tip formation can be clearly seen.

Fig. 15 shows the surface roughness measurements as a function of speed for various uncut chip thickness values. It is interesting to see that surface roughness ( $\mathrm{Rz}$ ) values improve around $62 \mathrm{~m} / \mathrm{min}$ cutting speed, corresponding with high cutting and thrust force values (Fig. 12). After $62 \mathrm{~m} / \mathrm{min}$ cutting speed, the surface quality deteriorates significantly mainly due to scratching effect of BUE. The results indicate that there exists a complex relationship between uncut chip thickness, cutting speed, BUE formation, and surface roughness. Relatively better surface quality values were obtained at lower uncut chip thickness values.

In Fig. 15, at $0.2 \mu \mathrm{m}$ uncut chip thickness, average surface roughness $\left(R_{z}\right)$ value of $0.13 \mu \mathrm{m}$ was measured. As for $0.4 \mu \mathrm{m}$ uncut chip thickness, average surface roughness $\left(R_{z}\right)$ value of $0.16 \mu \mathrm{m}$ was measured. It must be noted that the Rz and uncut chip thickness values are quite close to each other. In order to observe the chip formation during micro scale machining, a high speed microscope (Keyence VW 9000 series) is used. Due to limitations of the high speed microscope, the recording was only made from the backside of the chip. Based on the video recordings, under $0.4 \mu \mathrm{m}$ uncut chip thickness value, the chip formation transitioned from continuous to discontinuous. The media files attached to the online version of the paper clearly show continuous (Video 1 for $0.8 \mu \mathrm{m}$ uncut chip thickness) and intermittent (Video 2 for $0.2 \mu \mathrm{m}$ uncut chip thickness) machining cycles. It must be noted that in the experimental setup used in this study, the workpiece is continuously fed 
towards the cutting edge. Therefore, intermittent chip formation is expected when uncut chip thickness is less than minimum chip thickness. Based on these findings, the transition from continuous to intermittent chip formation happens around $0.4 \mu \mathrm{m}$. Assuming that edge radius is $4 \mu \mathrm{m}$, the minimum uncut chip thickness in the presence of BUE is around $10 \%$ of the edge radius. This ratio is smaller than those reported for stagnation point assumption in literature.

\section{Conclusions}

This study investigates the influence of built-up edge on tool wear, forces, and surface roughness under micro scale machining conditions. The uncut chip thickness, cutting speed, and clearance angle are considered as process variables. Based on our findings:

- A stable BUE formation exists under micro scale machining conditions of the titanium alloy Ti6Al4V considered in this study.

- During break-in period, the cutting edge radius increases which promotes BUE formation, protecting the tools from crater and flank wear. EDX analysis of the insert surface indicated a small change in the chemical analysis of the surface. But it is not as significant as those in macro scale machining processes.

- Machining input conditions are shown to affect the size and shape of BUE, which affect machining forces and surface roughness values. A cutting speed of $62 \mathrm{~m} / \mathrm{min}$ resulted in larger forces and better surface roughness values.

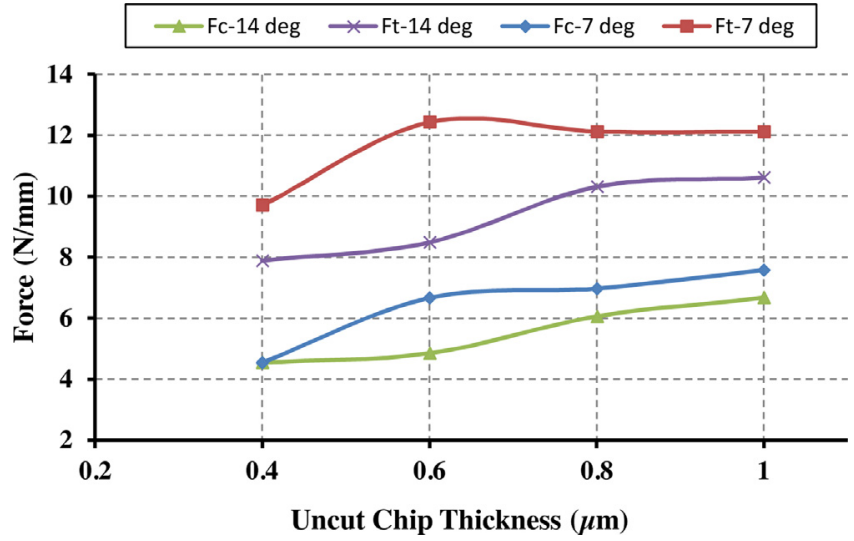

Fig. 13. Mean values of cutting and thrust forces at $62 \mathrm{~m} / \mathrm{min}$ cutting speed for cutting edges.

- Our findings confirm the influence of surface roughness on minimum uncut thickness. In the presence of BUE, the ratio of uncut chip thickness to edge radius is calculated to be around $10 \%$.

\section{Acknowledgements}

The authors would like to thank The Scientific and Technological Research Council of Turkey (TÜBITAK-110M660, National
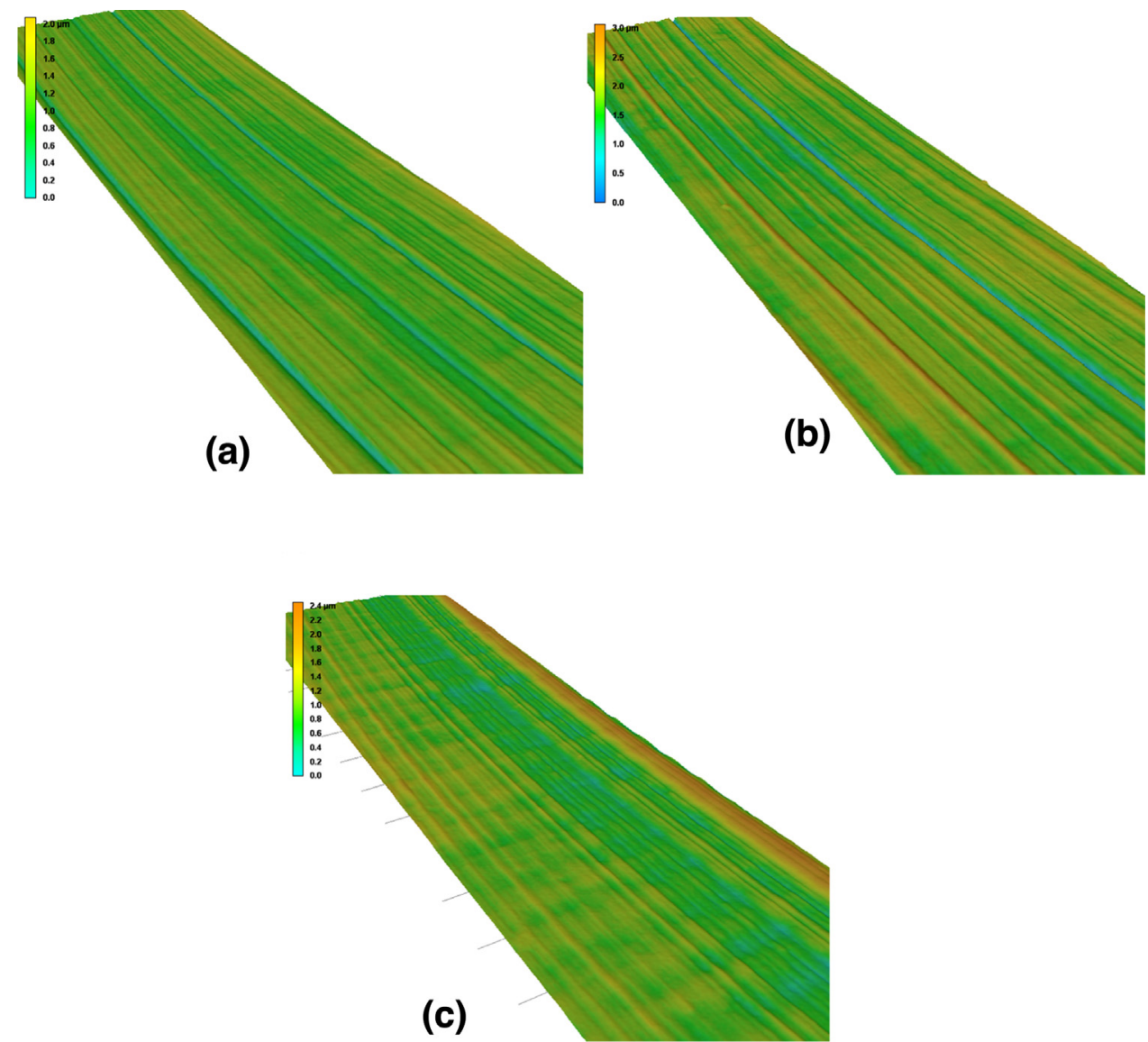

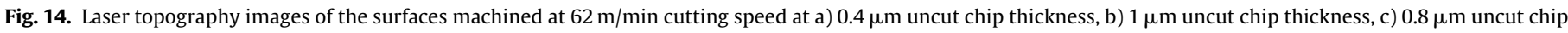
thickness at $78 \mathrm{~m} / \mathrm{min}$ (with $300 \times$ height magnification). 


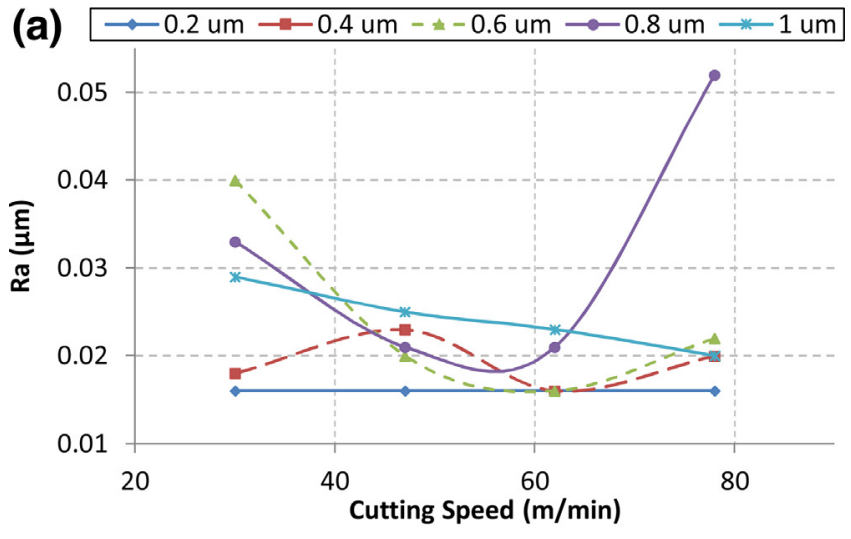

(b)

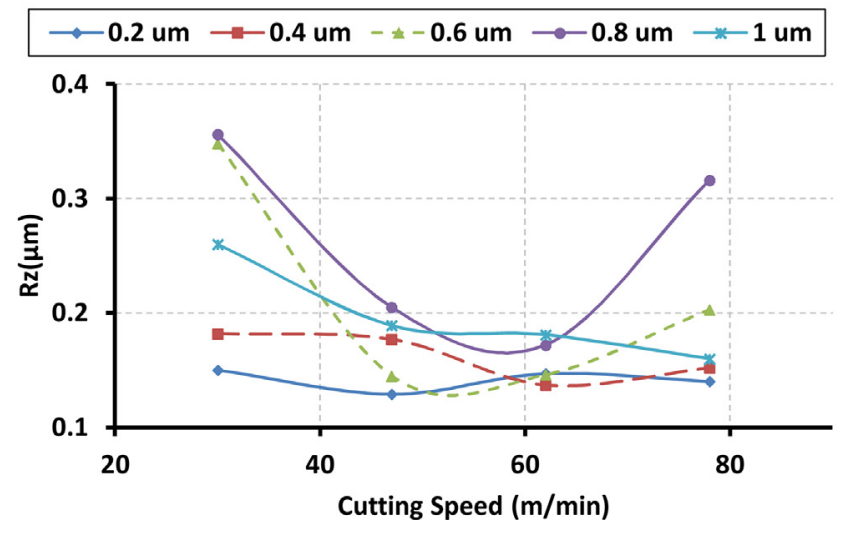

Fig. 15. Surface roughness analysis as a function of cutting speed (a) Ra, (b) Rz.

Young Researcher Career Development Program) and State Planning Organization of Turkey (HAMIT-Micro System Design and Manufacturing Research Center).

\section{Appendix A. Supplementary data}

Supplementary data associated with this article can be found, in the online version, at http://dx.doi.org/10.1016/j.jmatprotec.2016. 04.010.

\section{References}

Armendia, M., Garay, A., Iriarte, L.M., Arrazola, P.J., 2010. Comparison of the machinabilities of Ti6Al4V and TIMETAL 54M using uncoated WCCo tools. J. Mater. Process. Technol. 210, 197-203.

Arrazola, P.J., Garay, A., Iriarte, L.M., Armendia, M., Marya, S., Le Maitre, F., 2009 Machinability of titanium alloys (Ti6AlV and Ti555.3). J. Mater. Process. Technol. 209, 2223-2230.

Attanasio, A., Marcello Gelfi, M., Pola, A., Ceretti, E., Giardini, C., 2013. Influence of material microstructures in micromilling of Ti6Al4V alloy. Materials 6 , 4268-4283, http://dx.doi.org/10.3390/ma6094268.

Childs, T.H.C., 2013. Ductile shear failure damage modelling and predicting built-up edge in steel machining. J. Mater. Process. Technol. 213, 1954-1969.

Cuba Ramos, A., Autenrieth, H., Straußa, T., Deuchert, M., Hoffmeister, J., Schulze, V., 2012. Characterization of the transition from ploughing to cutting in micro machining and evaluation of the minimum thickness of cut. J. Mater. Process. Technol. 212, 594-600.

Denkena, B., Biermann, D., 2014. Cutting edge geometries. CIRP Ann.-Manuf. Technol. 63, 631-653.

Dornfeld, D., Min, S., Takeuchi, Y., 2006. Recent advances in mechanical micromachining. CIRP Ann.-Manuf. Technol. 55 (2), 745-768.
Ezugwu, E.O., Wang, Z.M., 1997. Titanium alloys and their machinability-a review. J. Mater. Process. Technol. 68, 262-274.

Fang, N., Dewhurst, P., 2005. Slip-line modeling of built-up edge formation in machining. Int. J. Mech. Sci. 47, 1079-1098.

Gerez, J.M., Sanchez-Carrilero, M., Salguero, J., Batista, M., Marcos, M., 2009. A SEM and EDS based study of the microstructural modifications of turning inserts in the dry machining of Ti6Al4V Alloy. AIP Conf. Proc. 1181, 567-574.

Hartung, P.D., Kramer, B.M., 1982. Tool wear in titanium machining. Ann. CIRP 32, 75-80.

Ikawa, N., Shimada, S., Tanaka, H., 1992. Minimum thickness of cut in micromachining. Nanotechnology 3, 6-9.

Ikuta, A., Shinozaki, K., Masuda, H., Tamame, Y., Kuroki, H., Fukaya, Y., 2002. during the cutting process. J. Mater. Process. Technol. 127, 251-255.

Jun, M.B.G., DeVor, R.E., Kapoor, S.G., Liu, X., 2006. Investigation of the dynamics of microend milling-part II: model validation and interpretation. J. Manuf. Sci. Eng. 128 (4), 901-912.

Kümmel, J., Gibmeier, J., Müller, E., Schneider, R., Schulze, V., Wanner, A., 2014 Detailed analysis of microstructure of intentionally formed built-up edges for improving wear behaviour in dry metal cutting process of steel. Wear 311, 21-30.

Kümmel, J., Braun, D., Gibmeier, J., Schneider, J., Greiner, C., Schulze, V., Wanner, A., 2015. Study on micro texturing of uncoated cemented carbide cutting tools for wear improvement and built-up edge stabilisation. J. Mater. Process. Technol. $215,62-70$.

Kalpakjian, S., Schmid, S., 2010. Manufacturing Engineering and Technology, 6th ed. Prenctice Hall, Singapore, pp. 563-564.

Karpat, Y., Özel, T., 2008. Mechanics of high speed cutting with curvilinear edge tools. Int. J. Mach. Tools Manuf. 48, 195-208.

Karpat, Y., 2009. Investigation of the effect of cutting tool edge radius on material separation due to ductile fracture in machining. Int. J. Mech. Sci. 51 (7), 541-546.

Kim, C., Mayor, J.R., Ni, J., 2004. A static model of chip formation in microscale milling. J. Manuf. Sci. Eng. 126 (4), 710-718.

Liu, X., DeVor, R.E., Kapoor, S.G., Ehmann, K.F., 2004. The mechanics of machining at the microscale: assessment of the current state of the science. J. Manuf. Sci. Eng. 126 (4), 666-678.

Lucca, D.A., Rhorer, R.L., Komanduri, R., 1991. Energy dissipation in the ultraprecision machining of copper. Ann. CIRP 40, 69-72.

Lucca, D.A., Rhorer, R.L., Komanduri, R., 1993. Effect of tool edge geometry on energy dissipation in ultraprecision machining. Ann. CIRP 42, 83-86.

Malekian, M., Mostofa, M.G., Park, S.S., Jun, M.B.G., 2012. Modeling of minimum uncut chip thickness in micro machining of aluminum. J. Mater. Process. Technol. 212, 553-559.

Pramanik, A., Littlefair, G., 2015. Machining of titanium alloy (Ti-6Al-4V)-theory to application. Mach. Sci. Technol.: Int. J. 19, 1-49, http://dx.doi.org/10.1080/ 10910344.2014.991031.

Son, S.M., Lim, H.S., Ahn, J.H., 2005. Effects of the friction coefficient on the minimum cutting thickness in micro cutting. Int. J. Mach. Tools Manuf. 45, 529-535.

Thepsonthi, T., Özel, T., 2015. 3-D finite element process simulation of micro-end milling Ti-6Al-4V titanium alloy: experimental validations on chip flow and tool wear. J. Mater. Process. Technol. 221, 128-145.

Waldorf, D.J., DeVor, R.E., Kapoor, S.G., 1999. An evaluation of ploughing models for orthogonal machining. J. Manuf. Sci. Eng. 121, 550-558.

Weule, H., Huntrupl, V., Tritschlerl, H., 2002. Micro cutting of steel to meet new requirements in miniaturization. CIRP Ann.-Manuf. Technol. 50, 61-64.

Woon, K.S., Rahman, M., Neo, K., Liu, S., 2008. The effect of tool edge radius on the contact phenomenon of tool-based micromachining. Int. J. Mach. Tools Manuf. 48 (12-13), 1395-1407.

Yussefian, N.Z., Koshy, P., Buchholz, S., Klocke, F., 2010. Electro-erosion edge honing of cutting tools. CIRP Ann. - Manuf. Technology 59, 215-218. 